\title{
EQUITATIVA SUFICIÊNCIA DE OPORTUNIDADES
}

\author{
Leandro Martins \\ Zanitelli
}

\section{Resumo}

O artigo expõe alguns problemas a que se sujeita o princípio da equitativa igualdade de oportunidades de Rawls. Afirma-se que um princípio alternativo de suficiência de oportunidades, a "equitativa suficiência de oportunidades" (ESO), é menos suscetível a esses problemas. Observa-se, além disso, que alguns argumentos em defesa da igualdade de oportunidades são mais bem sucedidos quando tratados como argumentos em favor de um princípio de suficiência como a ESO. O trabalho esclarece, por fim, por que a ESO pode ser entendida ou como princípio lexicamente superior ao princípio da diferença, ou como parte desse princípio.

Palavras-chave: Igualdade de Oportunidades; Rawls; Suficientismo; Igualitarismo; Princípio da Diferença

\section{INTRODUÇÃO}

Contrastando com a sua notória popularidade no discurso político brasileiro, o princípio da equitativa igualdade de oportunidades (EIO), ao menos na versão (não correspondente, diga-se de passagem, à mera igualdade "formal") em que aparece na teoria da justiça de Rawls, é academicamente contestado (ALEXANDER, 1985; ARNESON, 1999; 2013). Há dúvida não apenas sobre a validade do princípio em si, como também sobre a prioridade léxica que Rawls lhe atribui em relação ao princípio da diferença (RAWLS, 1999, p. 53-57; 77), cuja implicação é a de que a EIO deveria ser assegurada ainda que à custa de uma considerável redução das expectativas dos cidadãos em pior situação quanto à riqueza e à renda. ${ }^{2}$

\footnotetext{
${ }^{1}$ Doutor em Direito pela Universidade Federal do Rio Grande do Sul (UFRGS); Professor no Centro Universitário Ritter dos Reis (UniRitter). E-mail: leandrozanitelli@gmail.com

${ }^{2} \mathrm{O}$ próprio Rawls manifesta dúvida sobre a prioridade léxica do princípio da equitativa igualdade de oportunidades sobre o da diferença em uma versão reformulada da teoria da justiça. Ver Rawls (2001, p. 163 e nota de rodapé 44). Além disso, em contraste com a primazia do princípio das liberdades vol.08, $\mathrm{n}^{\circ}$. 01, Rio de Janeiro, 2015. pp 162-185 162
} 
Neste artigo, examino três objeções à EIO, as quais designo, respectivamente, como Problemas do Nivelamento por Baixo, da Classe Média e do Custo. Meu propósito é, primeiro, verificar em que medida a EIO é vulnerável aos referidos problemas, tanto na versão concebida por Rawls, em que somente se requer igualdade de oportunidades para cidadãos com iguais aptidões inatas (versão Sensível a Talentos), como em uma outra na qual essas mesmas aptidões são desconsideradas (versão Insensível a Talentos). Pretendo também, em segundo lugar, avaliar as chances de sucesso de uma versão suficientista da EIO, a equitativa suficiência de oportunidades (ESO). Princípios distributivos podem ser concebidos ora como princípios de igualdade, ora de prioridade e ora de suficiência. Enquanto o que se demanda no caso de um princípio de igualdade é igual distribuição de um ou mais bens, o importante para um princípio de prioridade é aumentar o quinhão de bens de cada um, tendo esse aumento tanto maior importância quanto pior a situação daquele de cujo quinhão se trata. Princípios de suficiência, por sua vez, definem um limiar a ser alcançado para todos os envolvidos, mostrando-se indiferentes à distribuição de bens acima desse limiar.

Tanto os ataques já referidos como as tentativas de justificação da EIO (TAYLOR, 2004; SHIFFRIN, 2004) costumam ter em vista a versão igualitária desse princípio. É oportuno, então, verificar em que pé os mesmos argumentos a favor e contra quando o que se tem em vista é a versão suficientista do princípio das oportunidades. Minhas conclusões a respeito são, em suma, as seguintes. Primeiro, a ESO é, em considerável medida, menos vulnerável do que a EIO aos Problemas do Nivelamento por Baixo, da Classe Média e do Custo. Segundo, argumentos empregados em defesa da EIO também servem para justificar a ESO e, em alguns casos (dos argumentos que denominarei como Argumentos de Bens Atrelados), são mais apropriados como argumentos em favor da ESO do que da EIO. Terceiro, é plausível que a ESO seja lexicamente superior ao princípio da diferença entendido como princípio atinente unicamente à distribuição de riqueza e renda (princípio da diferença na Versão Simples). Em uma outra versão (Versão Complexa) na qual impõe a maximização das expectativas dos cidadãos em pior situação quanto a um index de bens

básicas, em favor da qual Rawls argumenta exaustivamente, há poucas indicações em "Uma Teoria da Justiça" sobre as razões para a superioridade do princípio da equitativa igualdade de oportunidades em relação ao da diferença. 
primários composto não apenas pelos bens da riqueza e da renda, é provavelmente mais apropriado tratar a ESO como parte do princípio da diferença ao invés de como princípio independente e lexicamente superior a ele.

O artigo é organizado como segue. A primeira seção contém alguns esclarecimentos sobre a EIO. Na segunda seção, trata-se dos três problemas (Nivelamento por Baixo, Classe Média e Custo) da EIO nas duas versões antes citadas, Sensível e Insensível a Talentos. A terceira seção volta-se para a ESO, examinando em que medida ela é afligida pelos mesmos problemas, bem como se argumentos apresentados com o fim de justificar a EIO prestam-se também a versão suficientista desse princípio. A quarta seção examina a prioridade léxica da ESO sobre o princípio da diferença.

\section{ALGUMAS DEFINIÇÕES}

Rawls define a equitativa igualdade de oportunidades (EIO) em contraposição ao princípio da igualdade formal de oportunidades ou das “carreiras abertas a talentos". De acordo com o princípio da igualdade formal de oportunidades, todos possuem direitos legais iguais de acesso a posições (RAWLS, 1999, p. 62). Já a equitativa igualdade de oportunidades, ao invés de se contentar com a mera falta de impedimentos legais, requer que todos os cidadãos tenham uma chance equânime (fair chance) de ocupar posições de vantagem (RAWLS, 1999, p. 63). Esclarecendo o que uma "chance equânime" significa, Rawls (ibid.) diz que, a fim de atender à EIO:

"os que possuem talentos e habilidades em um mesmo patamar e estão igualmente dispostos a fazer uso deles devem ter as mesmas perspectivas de sucesso, independentemente do seu lugar inicial no sistema social. Em todos os setores da sociedade, as perspectivas culturais e de realização devem ser aproximadamente as mesmas para os similarmente dotados e motivados. As expectativas dos cidadãos com iguais habilidades e aspirações não devem sofrer a influência da classe social.”3

\footnotetext{
${ }^{3}$ No original: "those who are at the same level of talent and ability, and have the same willingness to use them, should have the same prospects of success regardless of their initial place in the social system. In all sectors of society there should be roughly equal prospects of culture and achievement for everyone similarly motivated and endowed. The expectations of those with the same abilities and aspirations should not be affected by their social class."
} 
Essa definição da EIO se baseia, portanto, em uma diferença entre três ordens de fatores determinantes das chances de cada um, a saber, aptidões inatas, circunstâncias sociais e motivação. Isso suscita um problema, porque o último fator pode não ser independente das demais. É possível, em outras palavras (provável, até), que a motivação de cada um para perseguir posições seja em alguma medida uma função de características inatas e do meio social (ALEXANDER, 1985, p. 201). Tendo em vista essa dificuldade, ignorarei, no que segue, o fator motivacional. ${ }^{4}$ Consideradas os demais fatores, é possível então distinguir duas versões da EIO:

Sensível a Talentos: "Para cidadãos cujas aptidões naturais sejam as mesmas, as chances de ocupar posições de vantagem devem ser iguais."

Insensível a Talentos: "As chances de ocupar posições de vantagem devem ser iguais para todos, independentemente das aptidões naturais de cada um."

Com a ressalva feita acerca da motivação, Sensível a Talentos é, como se percebe nas passagens transcritas acima, a versão mais próxima da EIO de Rawls. À primeira vista, Insensível a Talentos deve parecer implausível. Ela requer, por exemplo, que dois cidadãos, um deles enormemente dotado musicalmente e o outro não, tenham a mesma chance de reger uma orquestra. Não há, entretanto, um meio palatável de realizar isso. ${ }^{5}$ Como veremos adiante, contudo, Insensível a Talentos ganha em plausibilidade quando se consideram versões menos ambiciosas da EIO. ${ }^{6}$

\section{EIO COMO PRINCÍPIO DE IGUALDADE}

Nesta seção, tratarei dos problemas que a EIO enfrenta uma vez interpretada como princípio de igualdade. Observe que, como princípio assim, a EIO impõe

\footnotetext{
${ }^{4}$ Um problema de ignorar motivações é o mencionado por Arneson (1999, p. 78-79): não deveríamos deixar que as chances de sucesso variem de acordo com as ambições dos cidadãos? A resposta depende de saber se EIO deve ou não ser atendida ao longo de toda a vida. Considere uma interpretação da EIO segundo a qual é suficiente que as chances dos cidadãos sejam as mesmas a uma idade baixa o bastante para que não pareça contraintuitivo deixar de lado as ambições desenvolvidas até então. Diferenças de ambição verificadas após essa idade não seriam, assim, uma ameaça à EIO.

${ }^{5}$ Uma solução seria designar o chefe da orquestra por sorteio. Outra, de consequências menos desastrosas mas eficácia duvidosa e, de um modo geral, também pouco atraente, consiste em investir pesadamente no treinamento musical do cidadão inapto, procurando compensar, assim, a sua desvantagem natural.

${ }^{6}$ Insensível a Talentos tem a óbvia vantagem de não requerer que se determine a importância relativa das contingências naturais e sociais para as chances de sucesso. Para uma revisão recente da pesquisa empírica sobre a persistência de desigualdades de renda (entre outras) de geração para geração e a dificuldade para discriminar suas causas, ver Black e Devereux (2010).
} 
igualdade de chances, nada menos. Tendo em vista, ainda, as relações de prioridade entre as diferentes partes da concepção de justiça de Rawls, deve-se entender que o requerimento de igualdade da EIO somente pode ser deixado de lado devido a considerações baseadas no primeiro princípio da justiça, o princípio das liberdades. Ao longo da seção, terei como referência a versão Sensível a Talentos da EIO. Mais ao final, voltarei a atenção para a versão Insensível a Talentos.

\section{Sensível a Talentos}

Entendida como princípio de igualdade, a EIO põe-se diante de ao menos três problemas, a saber: o do Nivelamento por Baixo (levelling down), o da Classe Média, e o do Custo. Examino-os a seguir.

\section{Problema do Nivelamento por Baixo}

O Problema do Nivelamento por Baixo aflige princípios de igualdade em geral, desde que entendidos como princípios sobre estados de coisas ou de "igualdade télica" (PARFIT, 1997, p. 206; 210-211). Atribui-se a qualquer princípio de igualdade a implicação de que se deva tratar como moralmente valioso o fato de A e B possuírem a mesma quantidade do bem $x$, ainda que esse resultado se obtenha à custa de uma perda para uma das partes e nenhum ganho para a outra. Por exemplo, imagine que A possua $4 x$ e B $2 x$. De acordo com a objeção, um princípio de igualdade faz com que haja uma razão para passar a uma outra situação na qual A e B possuem apenas $2 x$. Ainda que a razão em questão não seja peremptória, mas meramente prima facie, isto é, que o princípio da igualdade não necessariamente requeira nivelar por baixo depois de tudo considerado, afirma-se que o simples fato de oferecer uma razão para uma diminuição das posses de A sem nenhum aumento para B basta para tornar a igualdade contraintuitiva.

Pode-se pensar que o Problema do Nivelamento por Baixo é mais ameno quando se trata da EIO pelo fato de ela se referir a um bem posicional. Diz-se que um bem é posicional quando uma perda para alguma das partes vem necessariamente acompanhada de um ganho para outra. Ao menos quando concebida em termos probabilísticos, a oportunidade para ocupar posições de vantagem é um bem assim. 
Suponha que a probabilidade atual de A chegar a uma certa posição seja de $x$, e que sejam tomadas medidas para reduzir essa probabilidade para $x-n$. Mantendo-se constante o número de posições de vantagem, a diminuição da probabilidade de $\mathrm{A}$ implica um aumento total de $n$ na probabilidade de outros ocuparem a posição em questão. $^{7}$

A importância de a oportunidade ser um bem posicional reside no fato de que $o$ Problema do Nivelamento por Baixo não existe para esses bens (Brighouse e Swift 2006). A objeção do Nivelamento por Baixo acusa a igualdade de atribuir valor moral prima facie a uma alteração do estado de coisas que resulte em uma distribuição igual a despeito de essa alteração não trazer consigo uma melhora na situação de cada um dos envolvidos. Ocorre que isso é impossível no caso de um bem posicional, já que qualquer redução do quinhão de uma das partes necessariamente traz consigo um ganho para alguém. Imagine que haja apenas dois cidadãos, A e B, e apenas uma posição a ser ocupada. Se, inicialmente, a probabilidade de A ser o escolhido for de o,8, qualquer medida pela qual se diminuam as chances de A necessariamente aumentarão as de $\mathrm{B}$.

Ainda, no entanto, que a EIO se refira a um bem posicional, o Problema do Nivelamento ressurge quando se consideram os efeitos de medidas para a realização da EIO sobre outros bens que não a oportunidade para ocupar posições de vantagem. Salvo alguma estipulação adicional, a EIO não impede medidas para a sua realização que, em relação a outros bens, apenas piorem a situação de alguns sem melhorar a de mais ninguém. Por exemplo, se uma das causas da desigualdade de oportunidades for a superior qualidade do ensino pago sobre o que é oferecido pelo estado gratuitamente, uma medida que se limitasse a proibir o ensino pago, forçando os filhos de famílias abastadas a frequentar a escola pública, seria compatível com a EIO. Embora não se possa dizer que uma medida assim tenha o efeito de nivelar por baixo oportunidades (já que ela plausivelmente aumenta as chances de estudantes pobres), esse pode ser o seu efeito quanto a um outro bem, o da educação, se a proibição ao ensino privado não ocasionar melhora na qualidade do ensino público.

\footnotetext{
${ }^{7}$ Repare, entretanto, que pode ser incorreto classificar o bem objeto da EIO como bem posicional quando não são constantes o número de posições de vantagem e o de candidatos a essas posições. Se, por exemplo, o número de posições puder sofrer variação negativa, corre-se o risco de que o estreitamento das diferenças de oportunidade se faça à custa meramente da redução das oportunidades dos que estão em melhor situação.
} 
No caso da EIO, o Problema do Nivelamento por Baixo torna-se mais agudo quando se aceitam as relações de prioridade léxica entre os princípios da justiça. Uma das defesas do igualitarismo contra a objeção do Nivelamento por Baixo consiste, como visto, em afirmar que, não sendo a igualdade o único valor, a razão para nivelar por baixo é uma razão tão-somente prima facie, cuja força seria no mais das vezes sobrepujada pela de razões contrapostas baseadas em outros valores (PARFIT, 1997, p. 211). Uma vez evitados, assim, os resultados indigestos que adviriam de uma versão monista do igualitarismo, fica-se em posição mais confortável para afirmar que a igualdade tem, mesmo (e ainda quando obtida à custa apenas de perdas), um valor moral intrínseco (TEMKIN, 2003, p. 67-68). Essa saída pluralista, entretanto, não está totalmente franqueada para quem, como Rawls, postula uma estrita prioridade da EIO sobre o princípio de distribuição da riqueza e da renda, o princípio da diferença (RAWLS, 1999, p. 53-57; 77).

Problema da Classe Média

O Problema da Classe Média está em boa medida relacionado à prioridade léxica da EIO sobre o princípio da diferença. Em uma das suas formulações mais comuns, esse princípio requer a maximização das expectativas dos cidadãos em pior situação quanto a certos bens primários (RAWLS, 1999, p. 68; 2001, p. 42-43). A preocupação com os cidadãos em pior situação, justificável tendo em vista o autointeresse das partes na posição original, parece ser, contudo, contraditada pela primazia atribuída à EIO. Devido a essa primazia, acaba-se tendo que preferir um arranjo institucional que em certo sentido atenda ao interesse de cidadãos de classe média (mais precisamente, o interesse por gozar de chances não inferiores às dos cidadãos do estrato mais elevado) em detrimento de outro sob o qual as expectativas dos cidadãos em pior situação sejam maximizadas (ARNESON, 1999, p. 82).

Em atenção ao Problema da Classe Média, pode-se argumentar que nem toda medida que reduza a diferença entre as oportunidades de cidadãos dos estratos alto e médio é necessariamente referendada pela EIO. Suponha que haja três cidadãos, A, B e C, situados, respectivamente, nos estratos alto, médio e baixo. Inicialmente, as chances de ocupar certas posições de vantagem são de o,6 para A, o,3 para B e o,1 para C. Uma medida que iguale, então, as chances de A e B e mantenha inalteradas as de C 
(resultando, assim, em uma distribuição de chances de 0,45 para A e B e o,1 para C) não seria imposta pela EIO porque, embora reduza as diferenças entre A e B e A e C, aumenta a distância entre B e C.

Uma resposta a esse argumento consistiria em dizer que, ainda que não requeira, tampouco há algo na versão sob exame da EIO que proíba a medida em favor de B. Salvo alguma estipulação adicional (por exemplo, que dê prioridade a reduzir as diferenças entre $\mathrm{B}$ e $\mathrm{C}$ ), o estado de coisas inicial imaginado acima não se mostraria nem mais nem menos conforme à EIO do que o final. Isso, entretanto, já não constitui um problema sério para um rawlsiano, uma vez que, se a medida em favor da classe média não é requerida pela EIO, então ela só poderá ter lugar (ao menos nos termos da concepção de justiça de Rawls) caso não contrarie o princípio da diferença, que é o princípio de justiça a aplicar subsequentemente à EIO. Uma medida que reduza a disparidade de chances entre os cidadãos A e B somente seria permitida, em outras palavras, caso não contrariasse o objetivo de maximizar as expectativas de $C$, o cidadão em pior situação.

O Problema da Classe Média ressurge, no entanto, quando se considera a hipótese de que, dos três cidadãos antes considerados, apenas os dos estratos alto e médio, A e B, sejam iguais em suas aptidões naturais (ALEXANDER, 1985, p. 204; ARNESON, 1999, p. 82-83). Nesta hipótese, se as chances de ocupar posições de vantagem forem inicialmente de o,6 para A, o,3 para B e o,1 para $C$, a EIO é não apenas compatível como requer que se igualem as chances dos dois primeiros, ainda que para isto seja preciso deixar A e B com o,45 de chances cada um e C com apenas o,1. ${ }^{8}$

\section{Problema do Custo}

A exemplo do anterior, o Problema do Custo também tem em vista a prioridade léxica que Rawls atribui à EIO em relação ao princípio da diferença. Uma vez aceita essa prioridade, a EIO, ainda que se limite a beneficiar os cidadãos em pior situação, pode ser acompanhada de uma piora das expectativas desses cidadãos em relação a certos bens primários. O Problema do Custo é, em suma, o de a igualdade de oportunidades

\footnotetext{
${ }^{8}$ Note, entretanto, que a única maneira de a EIO se mostrar completamente indiferente à sorte dos cidadãos em pior situação é a de que não haja nenhum cidadão das outras classes cujas aptidões naturais sejam idênticas às dos primeiros. É justamente a um cenário irrealista como esse que Arneson (1999, p. 82-83) alude ao tratar do Problema da Classe Média.
} 
ter de ser realizada ainda que em detrimento das expectativas dos cidadãos em desvantagem quanto aos bens primários (em particular, a riqueza e a renda) sujeitos ao princípio da diferença.

Uma das razões para temer o Problema do Custo é que a EIO pode demandar investimento maciço de recursos (por exemplo, em educação) para reduzir as diferenças de oportunidades entre jovens de famílias ricas e pobres (ALEXANDER, 1985, p. 202). Em lugar de investidos na igualdade de oportunidades, esses recursos poderiam ser usados de maneira a elevar as expectativas dos cidadãos em pior situação quanto a outros bens primários, por exemplo, em programas de renda mínima ou de combate ao desemprego. ${ }^{9}$

Outra razão para imaginar que a realização da EIO venha acompanhada de uma significativa piora das expectativas dos cidadãos em desvantagem é que a desigualdade de oportunidades pode ser um importante incentivo para a produção. Um motivo para que os cidadãos procurem acumular riqueza por meio do trabalho é o de elevar as chances de que seus filhos venham a ocupar posições de vantagem no futuro. Assim, quando se tomam medidas para que as chances de ocupar essas posições sejam as mesmas para todos, o referido incentivo para o trabalho desaparece, o que pode ocasionar uma redução geral da produção e a consequente piora das expectativas dos cidadãos em pior situação quanto à riqueza e à renda.

Por fim, vale observar também que não há nada na EIO (não, ao menos, na versão que estamos considerando) que a impeça de ser realizada mediante uma mudança nas posições de vantagem. Imagine uma sociedade na qual o ensino da matemática seja um fator determinante das diferenças de oportunidades, e na qual se constate que, mantidas as posições de vantagem atuais, é impossível anular esse fator (por exemplo, devido à influência dos pais). Uma solução para realizar a EIO consistiria então em suprimir as posições de vantagem para as quais a matemática se mostre particularmente importante. Em uma sociedade na qual as posições de vantagem sejam redefinidas de tal maneira, a desigualdade de oportunidades entre bons e maus

\footnotetext{
${ }^{9}$ Contra isso, poder-se-ia alegar que a EIO não necessariamente requer investimento considerável de recursos, já que, ao invés de aumentar os gastos com o ensino público, as diferenças de oportunidade poderiam ser diminuídas com restrições ou até a proibição do ensino privado. Tal como observado anteriormente, contudo, é possível que estratégias menos dispendiosas de realização tal como a recém mencionada tornem a EIO mais vulnerável ao Problema do Nivelamento por Baixo.
} 
matemáticos desapareceria. É escusado dizer, no entanto, que o emprego disseminado da estratégia de redefinir posições de vantagem a fim de promover a EIO pode ser danoso para todos, inclusive para os cidadãos em pior situação (ALEXANDER, 1985, p. 204).

\section{Insensível a Talentos}

Passemos a examinar agora a importância dos problemas acima mencionados para a versão Insensível a Talentos da EIO. Convém antes observar que, na versão em questão, a EIO escapa à objeção de tratar desigualmente duas ordens de fatores igualmente arbitrários, as aptidões naturais e as contingências sociais (ALEXANDER, 1985, p. 201). Tal tratamento desigual não pode ser justificado pela impossibilidade de alterar a distribuição natural de aptidões (a "loteria natural"). Embora, de fato, essa distribuição não seja em grande medida controlável (não, ao menos, no estágio atual da ciência), as chances de alcançar posições de vantagem atreladas às aptidões naturais o são. ${ }^{10}$ É perfeitamente possível conceber, assim, políticas públicas que procurem reduzir diferenças de oportunidade entre cidadãos desiguais em suas aptidões inatas (por exemplo, políticas que privilegiem a educação dos naturalmente menos aptos) e que ao fazê-lo propendam, pois, para a realização da versão Insensível a Talentos da EIO.

Comparando-se as duas versões, a EIO na versão Insensível a Talentos se mostra igualmente vulnerável ao Problema do Nivelamento por Baixo, menos vulnerável ao Problema da Classe Média e mais vulnerável ao Problema do Custo. Em relação ao primeiro problema, viu-se acima que ele não existe quanto às oportunidades, já que elas (mantendo-se constantes as posições de vantagem e o número de candidatos a essas posições) caracterizam-se como bem posicional. É possível, porém, que medidas para a realização da EIO tenham o condão de influir sobre a distribuição de outros bens e que, em relação a esses bens, o efeito das referidas medidas apenas piore a situação de algumas das partes sem melhorar a de nenhuma outra. Isto é igualmente verdadeiro para as versões Sensível e Insensível a Talentos.

\footnotetext{
${ }^{10}$ Taylor (2004, p. 346) esboça um argumento em favor do tratamento diferenciado das contingências naturais e sociais. Segundo ele, a indiferença ao efeito das contingências sociais sobre as oportunidades é mais propensa a ser atribuída à ação humana e a parecer, como tal, degradante, constituindo, por esse motivo, uma ameaça ao autorrespeito mais séria do que a indiferença à desigual distribuição natural de aptidões.
} 
A razão pela qual o Problema da Classe Média não tem lugar sob a versão Insensível a Talentos é que essa versão elimina a possibilidade de a realização da EIO ser inócua para os cidadãos em pior situação. Na versão Sensível a Talentos, a EIO pode se mostrar indiferente aos interesses desses cidadãos caso eles sejam naturalmente menos aptos do que os demais. Supondo que haja equivalência de aptidões inatas apenas entre os cidadãos dos estratos alto e médio, Sensível a Talentos requererá medidas em favor dos cidadãos do estrato médio a fim de eliminar as diferenças entre as chances desses cidadãos e as dos cidadãos do estrato mais elevado. Na versão Insensível a Talentos, em contrapartida, a referida possibilidade desaparece. Salvo estipulação adicional que conceda prioridade a aumentar as chances dos cidadãos em pior situação, Insensível a Talentos se mostra indeterminada quanto a medidas que reduzam as diferenças de oportunidades entre os cidadãos dos estratos alto e médio e mantenham inalteradas as chances dos cidadãos do estrato baixo, uma vez que se, por um lado, promovem a igualdade no que se refere às camadas superiores, por outro essas medidas também alargam as diferenças entre os cidadãos em pior situação e os que lhes estão imediatamente acima.

O Problema do Custo, por sua vez, acirra-se em Insensível a Talentos. Sensível a Talentos exige ou que a sociedade invista para compensar desvantagens decorrentes de contingências sociais, ou então que abdique das vantagens de empregar os cidadãos favorecidos por essas contingências (por exemplo, distribuindo posições de vantagem mediante sorteio entre aqueles com aptidões inatas equivalentes). Isso se repete em Insensível a Talentos, com a diferença que se trata agora ou de investir para compensar os efeitos de contingências sociais e naturais ou de abdicar das vantagens de fazer uso dos cidadãos beneficiados por essas duas espécies de contingências.

\section{EIO COMO PRINCÍPIO DE SUFICIÊNCIA: EQUITATIVA SUFICIÊNCIA DE OPORTUNIDADES (ESO)}

Nesta seção, examino a hipótese de a EIO ser entendida como princípio de suficiência ao invés de igualdade. Antes, no entanto, gostaria de explicar por que um outro princípio distributivo, o de prioridade, não constitui uma alternativa atraente para a interpretação da EIO. 
Em contraste com o igualitarismo, o prioritarismo se caracteriza por ter em vista apenas a vantagem de cada um em termos absolutos (PARFIT, 1997, p. 212-214). Por exemplo, supondo que haja dois grupos de cidadãos, um em melhor e outro em pior situação, é irrelevante para um princípio de prioridade determinar o quanto cada grupo possui em relação ao outro (para o igualitarismo, em contraste, isso, e somente isso, é relevante). O prioritarismo trata qualquer melhora na situação de alguma das partes como moralmente relevante, e tão mais relevante quanto pior seja, em termos absolutos, a situação da parte beneficiada.

Pois bem, o que impede a EIO de ser entendida como princípio de prioridade? A dificuldade decorre do fato de o bem cuja distribuição a EIO regula ser um bem posicional. Em relação ao igualitarismo, o prioritarismo tem a vantagem de não deixar de atribuir valor moral à melhora da situação de alguém em termos absolutos, mesmo quando essa melhora tenha como resultado um aumento da desigualdade. Em outras palavras, o prioritarismo escapa ao Problema do Nivelamento por Baixo ao tratar como moralmente preferível um estado de coisas em que A e B têm, respectivamente, $2 x$ e $x$ a outro em que ambos tenham $x$. Ocorre que, quando se trata de um bem posicional, uma piora na situação de B nunca é apenas isso, já que vem necessariamente acompanhada de uma melhora na situação de A. O corolário disso é tornar as demandas do prioritarismo e do igualitarismo coincidentes (BRIGHOUSE e SWIFT, 2006, p. 475). Para ilustrar, imagine que A e B sejam as únicas partes envolvidas, e que haja uma medida capaz de elevar em o, 1 as chances de A (e, consequentemente, reduzir as de B na mesma proporção). Como o ganho de $\mathrm{A}$ é equivalente à perda de B, essa medida somente será chancelada pelo prioritarismo caso A tenha, inicialmente, menos chances do que $B$, pois essa é a condição necessária para que o ganho de A tenha maior peso moral do que a perda de B." O mesmo vale, contudo, para a igualdade. Se A já possui, de

\footnotetext{
${ }^{11}$ Acredito que qualquer versão plausível do prioritarismo avalie o peso do ganho de $\mathrm{A}$ e da correspondente perda de B de acordo com a situação final das partes. Em sendo assim, o fato de A ter inicialmente menos chances do que $B$ é uma condição necessária, mas não suficiente, a que a mudança cogitada acima seja referendada pelo prioritarismo. É que, em decorrência da mudança, A pode chegar a uma situação ainda melhor do que a situação inicial de B (por exemplo, se as probabilidades iniciais de A e B forem, respectivamente, de o,46 e o,54), caso no qual beneficiar A será menos importante do que evitar a perda de $B$. Mas o fato de o prioritarismo ter de preferir uma situação em que as chances de $\mathrm{A}$ são de 0,46 e as de $\mathrm{B}$ de 0,54 à outra em que essas chances passam a 0,56 e 0,44 apenas ratifica a asserção de que, em relação a bens posicionais, o igualitarismo e o prioritatismo são redundantes.
} 
início, mais chances de sucesso do que $\mathrm{B}$, aumentar as chances do primeiro em o,1 alargaria a diferença entre ambos, algo que a igualdade repudia.

Os princípios de igualdade e prioridade de oportunidades podem deixar de coincidir caso haja variação no número de posições de vantagem e de candidatos a essas posições. Em tal caso, o princípio de prioridade também se mostra vulnerável ao Problema do Nivelamento por Baixo, embora provavelmente de maneira atenuada. Na versão conforme ao prioritarismo, a EIO não reconhece valor à igualdade de oportunidades em si mesma, mas pode chancelar um aumento das chances dos que têm menos à custa de uma diminuição (mesmo que de maior proporção) das dos que têm mais. Esse aumento das chances dos cidadãos em pior situação pode ser conseguido, por sua vez, à custa de um nivelamento por baixo na distribuição de outros bens, como educação e renda. O princípio de prioridade de oportunidades também é afligida pelos Problemas da Classe Média (na versão Sensível a Talentos) e do Custo.

Consideremos agora a hipótese de a EIO ser entendida como princípio de suficiência. Segundo Casal (2007), duas teses podem ser relacionadas ao suficientismo, uma positiva e outra negativa. A tese positiva é a de que há valor moral no fato de as partes não se encontrarem abaixo de um certo limiar no que toca a certo bem ou bens. De acordo com a tese negativa, é moralmente irrelevante a distribuição de bens acima do citado limiar. Para ilustrar, suponha que o limiar seja 5 e que A e B possuam, respectivamente, 6 e 3. Para o suficientismo, esse estado de coisas deve ser preterido a um no qual A e B tenham ao menos 5 cada um (tese positiva). Além disso, o princípio de suficiência é indiferente entre dois estados de coisas em que A e B tenham alcançado esse limiar - por exemplo, entre um no qual A e B possuam, respectivamente, 6 e 5 e outro no qual possuam to e 5,5 .

Quando se cogita de um princípio de suficiência como interpretação da EIO rawlsiana, as duas teses mencionadas no parágrafo anterior podem ser reformuladas do seguinte modo. De acordo com a tese positiva, é lexicamente prioritário em relação às demais demandas da justiça (exceção feita às do princípio das liberdades básicas) que os cidadãos não estejam abaixo de um certo limiar quanto às chances de ocupar posições de vantagem. A tese negativa, por sua vez, traduz-se como a de que, acima do limiar em questão, a distribuição de oportunidades deixa de se submeter à EIO. Ao invés de 
moralmente irrelevante, pode-se entender essa distribuição (acima do limiar) é regulada então por outros princípios de justiça que não a EIO, entre eles o princípio da diferença.

Entendida como parte da concepção de justiça rawlsiana, o princípio da suficiência de oportunidades escapa a uma das críticas feitas ao suficientismo em geral, a saber, a de que a indiferença à distribuição de bens acima do limiar é contraintuitiva (ARNESON, 2005). ${ }^{12}$ Resta verificar, não obstante, se há uma versão suficientista plausível da EIO. Para comodidade da exposição (e também para evitar o uso do termo "igualdade" em relação a um princípio que não é, na interpretação a seguir cogitada, estritamente igualitário), referir-me-ei doravante à versão suficientista da EIO como "equitativa suficiência de oportunidades" (ESO).

Qualquer versão do princípio da ESO se caracteriza por definir uma probabilidade limiar de ocupar posições de vantagem. Que nenhum cidadão se encontre aquém desse limiar é algo requerido pela ESO e deve, portanto, ter primazia sobre a realização do princípio da diferença. Oportunidades acima do referido limiar são irrelevantes para o princípio, embora não precisem sê-lo de um modo geral. Lembre-se, ainda, que, tal como a EIO, a ESO pode se apresentar nas versões Sensível e Insensível a Talentos. É possível conceber um princípio de suficiência que combine essas duas versões ao definir dois limiares distintos, um abaixo do qual nenhum cidadão, independentemente das aptidões inatas, pode se encontrar e outro aplicável apenas a cidadãos com iguais aptidões inatas (bem como uma regra sobre como proceder quando os dois limiares não puderem ser simultaneamente atingidos). No que segue, terei em vista simultaneamente as hipóteses de uma ESO Sensível, Insensível a Talentos, e Mista (isto é, que combine as duas primeiras da maneira recém mencionada).

Tratemos agora da situação da ESO em relação aos três problemas expostos anteriormente, os do Nivelamento por Baixo, Classe Média e Custo. Uma vantagem da ESO em relação à EIO diz respeito ao Problema do Nivelamento por Baixo. Como

\footnotetext{
${ }^{12}$ Uma outra crítica, a de que o suficientismo privilegia a melhora da situação daqueles que se encontram logo abaixo do limiar em detrimento dos que estão ainda pior (em relação aos quais uma melhora de mesma magnitude seria insuficiente para chegar ao limiar) (Arneson, 2005), pode ser rebatida caso o princípio da suficiência seja redefinido de modo a tratar como "intrinsecamente mau que algumas pessoas estejam aquém do limiar, e tanto pior quanto mais distantes do limiar elas estiverem". Para versões de suficientismo que incluem essa estipulação, ver HUSEBY (2010) e SHIELDS (2012).
} 
observado anteriormente, esse problema não existe quanto às chances de ocupar posições de vantagem em si mesmas (desde que, ao menos, essas chances sejam entendidas como um bem posicional), mas é possível que certas medidas de atendimento à EIO tenham como resultado a piora (sem qualquer correspondente melhora) da situação de alguns cidadãos quanto à distribuição de outros bens. Para evitar isso, pode-se definir o limiar da ESO de maneira a que ele se considere atingido sempre que, a fim de elevar as chances de certos cidadãos, somente sejam possíveis medidas que tenham como efeito o nivelamento por baixo em relação à distribuição de outros bens. Supondo, para exemplificar, que o bem em questão seja a educação, a ESO pode estipular como limiar o de um estado de coisas no qual mais nenhum aumento das chances dos cidadãos em desvantagem se mostre possível a não ser mediante uma piora na qualidade do ensino oferecido a outros cidadãos. Deve-se observar, por outro lado, que o fato de a aplicação da ESO ter como resultado uma piora geral na distribuição de certo bem não é sempre indesejável ou indesejável na mesma medida. O limiar da ESO pode, pois, mostrar-se mais sensível quanto ao nivelamento por baixo na distribuição de alguns bens primários do que de outros.

O Problema da Classe Média é, como visto, restrito à versão Sensível a Talentos da EIO. Havendo equivalência de aptidões inatas entre cidadãos dos estratos alto e médio, mas não entre esses e os cidadãos em pior situação, a EIO requer igualdade de oportunidades entre os primeiros, o que pode ter de ser realizado por meios que atentem contra os interesses dos cidadãos do estrato mais baixo. Não é difícil perceber agora por que o Problema da Classe Média é no mínimo abrandado no caso da ESO, inclusive em uma versão Sensível a Talentos. Nas circunstâncias recém aludidas, a ESO não requer igualdade de oportunidades, mas tão-somente que as oportunidades dos cidadãos do estrato médio não fiquem aquém do limiar. Em comparação com a EIO, portanto, a ESO é menos tendente a requerer medidas que sacrifiquem os cidadãos pior situados a fim de elevar as chances dos cidadãos de classe média.

O Problema do Custo é também mais ameno na ESO. Quando se consideram os custos da igualdade de oportunidades, percebe-se como a ideia de um limiar tem consequências intuitivas: a partir de um certo ponto, é melhor que os cidadãos em pior situação tenham menos chances de ocupar posições de vantagem do que seguir aumentando essas chances até que a vantagem atrelada às referidas posições (por vol.08, $n^{\circ}$. 01, Rio de Janeiro, 2015. pp 162-185 176 
exemplo, devido a uma redução geral da riqueza e da renda) se torne desprezível. Isso vale inclusive para a versão Insensível a Talentos, em relação à qual o Problema do Custo é maior. A esse respeito, a ESO tem, , como antes observado, a vantagem de poder combinar as versões Sensível e Insensível a Talentos, definindo um limiar para cidadãos com iguais aptidões inatas e outro para cidadãos com diferentes aptidões. ${ }^{13}$

O fato de se mostrar menos vulnerável aos problemas que afligem a EIO não basta, entretanto, para concluir que a ESO seja um princípio válido. Segue-se podendo perguntar por que devemos atribuir importância (ainda que moderada) às chances de ocupar posições de vantagem, ao invés de simplesmente maximizar as expectativas dos cidadãos em pior situação quanto a certos bens relevantes. ${ }^{14}$

Pois bem, pretendo demonstrar agora como certos argumentos acerca da prioridade léxica da EIO sobre o princípio da diferença são mais bem sucedidos quando entendidos como argumentos em favor da ESO. Trata-se de argumentos que designarei como "Argumentos dos Bens Atrelados", porque chamam a atenção para a importância de bens aos quais as posições de vantagem costumam estar atreladas. Entre eles estão argumentos que apelam para o valor do trabalho, ou de um trabalho com certas características. Segundo Taylor (2004), o trabalho significativo, entendido como trabalho que atende ao que Rawls designa como princípio aristotélico (RAWLS, 1999, $\S 65)$, isto é, um trabalho que desafia progressivamente o desenvolvimento de uma ou mais capacidades humanas, é indispensável para a autorrealização. Como o interesse pela autorrealização é mais importante do que o interesse por riqueza e renda, justificase, segundo Taylor, a primazia da EIO sobre o princípio da diferença (entendido como princípio adstrito à riqueza e à renda). Shiffrin (2004, p. 1.666-1.669) também defende a EIO como oportunidade para o trabalho significativo, mas não só. Para ela, a EIO, ao diversificar as opções de trabalho, ajuda a tornar realizáveis diferentes concepções de bem. O trabalho (e a EIO, como princípio de acesso a ele) tem valor, ainda, por ser uma

\footnotetext{
${ }^{13}$ Por exemplo, supondo que $A$ e $B$ possuam aptidões naturais equivalentes e superiores às de $C$, a ESO pode definir um limiar de o,3 para A e B e outro de o,15 para C.

${ }^{14}$ Se a oportunidade é um bem relevante, ela pode ser incluída no index de bens primários acerca dos quais o princípio da diferença determina que as expectativas dos cidadãos em desvantagem sejam maximizadas. Isso, no entanto, é diferente de dar prioridade às chances de ocupar posições de vantagem (seja à igualdade de chances, seja a que essas chances não fiquem aquém de um limiar) em relação à distribuição de outros bens primários.
} 
fonte de status e uma base social do autorrespeito ao servir como meio de interação e estreitamento de relações.

Uma falha de Argumentos de Bens Atrelados consiste em confundir as chances de ocupar posições de vantagem com as de usufruir de certos bens aos quais essas posições costumam estar relacionadas. ${ }^{15}$ Considere-se, para exemplificar, o caso do trabalho significativo. Do fato de o trabalho significativo ser importante pode-se tirar uma razão em favor de um princípio que iguale (ou maximize para os cidadãos em pior situação) as chances de realizar um trabalho assim. Isso é diferente, todavia, de igualar as chances de ocupar posições de vantagem, ou é, ao menos, diferente se admitirmos que nem toda posição de vantagem envolve, ou envolve em mesma medida, trabalho significativo. No que se refere às chances de realizar trabalho significativo, pode ser preferível um estado de coisas no qual as chances de ocupar posições de vantagem são distribuídas de maneira desigual, mas há trabalho significativo em abundância, a um outro em que, embora as chances de ocupar posições de vantagem sejam iguais para todos, poucas dessas posições requeiram trabalho significativo. ${ }^{16}$

Quando o que se alega para embasar a EIO é uma característica do trabalho em geral, e não de alguns trabalhos (como no caso dos argumentos de Shiffrin sobre o trabalho como fonte de status e base social do autorrespeito), o problema recém aludido não somente volta a se apresentar, como a ele se acrescenta um outro. Primeiro, se é o trabalho que importa (ou algo que se obtém por meio dele), um estado de coisas no qual as chances de ocupar posições de vantagem sejam iguais pode não ser a melhor opção. Melhor do que tornar iguais as chances de ocupar posições de vantagem é aumentar a oferta de trabalho, a fim de maximizar as chances de trabalho dos cidadãos

\footnotetext{
${ }^{15} \mathrm{O}$ mesmo erro é encontrado em uma breve passagem na qual Rawls observa que as suas razões para defender a EIO não são meramente de eficiência (RAWLS, 1999, p. 73). Mesmo em uma sociedade na qual a falta de atenção à EIO se mostre eficiente, diz Rawls, aqueles aos quais fossem negadas iguais chances "teriam razão em se sentir injustamente tratados ainda que beneficiados pelo esforço daqueles aos quais fosse permitido ocupá-las [as posições de vantagem]. Eles teriam razão de se queixar por lhes serem negadas não apenas certas recompensas externas dos cargos, mas também a experiência de autorrealização que advém do exercício hábil e dedicado de deveres sociais. Esses cidadãos seriam privados, assim, de uma das principais formas de bem humano." (no original: "would be right in feeling unjustly treated even though they benefited from the greater efforts of those who were allowed to hold them. They would be justified in their complaint not only because they were excluded from certain external rewards of office but because they were debarred from experiencing the realization of self which comes from a skillful and devoted exercise of social duties. They would be deprived of one of the main forms of human good.")

${ }^{16}$ Para um crítica mais abrangente aos argumentos de Taylor e Shiffrin sobre a EIO (incluindo a ponderação feita acima), ver Arneson (2013, p. 320-327).
} 
em pior situação (mesmo que, para que esse objetivo maximizador seja alcançado, as chances desses cidadãos tenham de ser menores do que as dos demais). Em segundo lugar, é curioso que um argumento sobre o trabalho seja apresentado para a justificação de um princípio relativo às chances de ocupar posições de vantagem. Deve-se entender que todo trabalho (ou, ao menos, todo trabalho que seja fonte de status ou envolva interações propícias ao autorrespeito) é uma posição de vantagem, inclusive o trabalho tedioso e mal remunerado? Esse é, sem dúvida, um ponto de vista surpreendente, que leva a atribuir à EIO certas consequências contraintuitivas. Em sociedades nas quais há um excesso de oferta de trabalho braçal (e em que, portanto, esse trabalho é habitualmente mal pago), será um ideal o de que se tomem medidas para que todos (ou pelo menos aqueles com iguais aptidões inatas) tenham a mesma chance de realizar um trabalho assim?

Apesar de implausíveis como argumentos em defesa da EIO, Argumentos de Bens Atrelados são aptos à justificação da ESO. Ideias como a da autorrealização pelo trabalho (Taylor 2004) e a do trabalho como meio para a realização de diferentes concepções de bem, aquisição de status e base social do autorrespeito (SHIFFRIN, 2004, p. 1.666-1.669) não apenas oferecem uma razão para que todos tenham alguma chance de ocupar posições de vantagem (admitindo-se que tais posições estejam comumente atreladas aos bens em questão) como ajudam a definir um ou mais limiares da ESO. Por exemplo, a exigência de que todos tenham uma certa probabilidade de realizar um trabalho significativo define como limiar da ESO aquele no qual o acesso a posições de vantagem não deixe ninguém com chances de trabalho significativo inferiores às mínimas exigidas. A altura desse limiar dependerá então do quanto as posições de vantagem em uma determinada sociedade estão associadas a trabalho significativo. Em sociedades na qual a oferta desse trabalho é abundante (isto é, posições de vantagem geralmente ou quase sempre envolvem trabalho significativo), o limiar em questão pode ser mais baixo do que em sociedades nas quais o trabalho significativo é mais raro.

Argumentos mais bem sucedidos quando se trata de justificar a EIO são os Argumentos de Competição Justa" (fair competition). ${ }^{17}$ Ao invés de aludir aos bens atrelados a posições de vantagem, esses argumentos ressaltam a importância das chances de ocupar as referidas posições, importância essa que pode ser intrínseca ou

\footnotetext{
${ }^{17}$ A expressão é de Brighouse e Swift (2006, p. 475-477).
} 
derivada de algum outro bem, como o autorrespeito. Argumentos de Competição Justa são mais promissores do que Argumentos de Bens Atrelados porque dão ênfase às chances de ocupar posições de vantagem, e não ao que essas posições trazem consigo. Mesmo quando essas chances são importantes não intrinsicamente, mas como meio para a obtenção de outro bem, como o autorrespeito, o bem em questão é visto (no caso dos Argumentos de Competição Justa) como uma consequência direta das chances de sucesso, e não das posições a que essas chances se referem.

Argumentos de Competição Justa são, à primeira vista, aptos a justificar a EIO, pois se o que importa, afinal, são as chances de ocupar posições de vantagem, é bem possível que essas chances tenham que ser iguais. Disso não segue, contudo, que tais argumentos sejam incompatíveis com a ESO. Se as chances de ocupar posições de vantagem são valiosas, é provavelmente preferível um estado de coisas no qual elas sejam desiguais mas não estejam abaixo de um certo limiar a um outro no qual as chances de alguns cidadãos não atinjam esse limiar. ${ }^{18}$ Além disso, embora a EIO se mostre superior à ESO no que se refere à distribuição de chances em si, a ESO tem, como visto, outras vantagens, entre elas a de tornar palatável uma versão (Insensível a Talentos) na qual alguns cidadãos não sejam simplesmente desconsiderados devido a seus dotes naturais. Por fim, nos casos em que Argumentos da Competição Justa tratam as chances de ocupar posições de vantagem como meio para algum fim valioso, é possível que o fim em questão requeira algo menos do que uma estrita igualdade de chances e seja, portanto, plenamente realizável mediante a ESO e inapto, portanto, a justificar a EIO.

Um ponto acerca do qual a análise até aqui talvez tenha se mostrado pouco esclarecedora é o do limiar correspondente a ESO. Tomadas em conjunto, as considerações precedentes provavelmente implicam a existência não de um, mas de diversos limiares. Cogitou-se, em primeiro lugar, da possibilidade de limiares distintos para cidadãos com aptidões naturais iguais e desiguais. Além disso, para lidar com o Problema do Nivelamento por Baixo, afirmei também que a ESO poderia ser interpretada de maneira a não exigir que as chances de alguns cidadãos vão além do ponto em que, para que continuem se elevando, seja preciso reduzir a quantidade total

\footnotetext{
${ }^{18}$ Para uma defesa do ponto de vista segundo o qual Argumentos de Competição Justa embasam o suficientismo em relação a bens posicionais, ver Brighouse e Swift (2006, p. 476).
} 
a distribuir de certos bens sem ganho para quem quer que seja. Por último, Argumentos de Bens Atrelados e de Competição Justa (os segundos quando atribuam às chances de ocupar posições de vantagem uma importância derivada) ajudam a estipular um limiar em conformidade com a justificativa que oferecem para a ESO. Por exemplo, se as chances de ocupar posições de vantagem são importantes por causa do trabalho significativo ao qual essas posições costumam estar atreladas (um dos possíveis Argumentos de Bens Atrelados), pode-se definir como limiar aquele no qual as expectativas de trabalho significativo dos cidadãos em pior situação sejam maximizadas.

A coexistência de mais de um limiar torna a ESO um princípio intrincado. Essa parece ser, contudo, a única alternativa a uma conformação simplesmente arbitrária. Além disso, se, por um lado, é pouco provável que os vários limiares cogitados coincidam, por outro também não se trata (não, ao menos, obrigatoriamente) de limiares conflitantes. Por exemplo, se a justificativa para que as chances de ocupar posições de vantagem não fiquem aquém de um certo limiar reside na relação entre essas chances e o autorrespeito, uma vez alcançado esse limiar, não é preciso seguir perseguindo maior igualdade até o ponto em que isso torne necessário nivelar por baixo a distribuição de outros bens (isto é, até o ponto correspondente ao limiar concebido para fazer frente ao Problema do Nivelamento por Baixo).

\section{ESO E PRINCÍPIO DA DIFERENÇA}

A seção anterior afirmou que uma versão suficientista da EIO, ESO, é menos vulnerável aos Problemas do Nivelamento por Baixo, da Classe Média e do Custo, podendo ser defendida (em certos casos, até com mais propriedade) com argumentos como os de Bens Atrelados e Competição Justa. Isso pode ser suficiente para sugerir que a ESO é um princípio válido, mas é ainda pouco para concluir que ela deva ter a prioridade léxica sobre o princípio da diferença. Esta seção encerra o trabalho tratando da relação entre a ESO e o princípio da diferença.

O problema de justificar a supremacia de um princípio (qualquer princípio) sobre o princípio da diferença é que isso é como atacar um alvo móvel. Há diferentes versões do princípio da diferença, algumas das quais tornam a tese da prioridade léxica da ESO mais, e outras menos, fácil de defender. No que segue, considerarei duas versões 
que se distinguem unicamente quanto aos bens cuja distribuição o princípio da diferença regula. Em ambas as versões, esse princípio requer a maximização das expectativas do cidadãos em pior situação, mas em uma das versões, que designarei como Versão Simples, as expectativas em questão dizem respeito tão-somente à riqueza e à renda, enquanto na outra, a Versão Complexa, as expectativas a serem maximizadas são quanto a um index constituído por todos os bens primários cuja distribuição não tenha sido exaurida por algum princípio anterior ao da diferença.

Comecemos com a relação entre a ESO e a Versão Simples. ${ }^{19}$ Tendo em vista a importância de outros bens atrelados a posições de vantagem além da riqueza e da renda, bem como a importância (intrínseca ou derivada) das chances para ocupar essas posições, é plausível que, em alguma medida, o objetivo de maximizar as expectativas dos cidadãos em pior situação quanto à riqueza e a renda esteja subordinado a que as referidas chances (e as expectativas quanto aos bens a elas relacionados) alcancem um certo limiar. Vale lembrar, quanto a isso, que as relações de prioridade léxica entre princípios são peculiares ao que Rawls designa como concepção especial de justiça, uma concepção cuja validade é limitada a condições entre as quais se inclui a de uma certa disponibilidade de meios de subsistência (RAWLS, 2001, p. 47 e nota de rodapé 12). Sob condições como essas, é compreensível que se abra mão de um pouco de riqueza e renda a fim de prevenir uma desigualdade de chances corrosiva do autorrespeito ou que restrinja demasiadamente para alguns o acesso a bens como o trabalho e o trabalho significativo.

Algo diverso se passa na Versão Complexa, em que o princípio da diferença requer a maximização de um index de bens primários não limitado à riqueza e à renda. ${ }^{20}$ Ocorre que vários argumentos que se propõem a justificar a EIO (e a ESO) aludem a bens (como a autorrealização e o autorrespeito) que, na Versão Complexa, podem ser considerados parte do index cuja maximização o princípio da diferença impõe. Isso não só pode como deve ser assim, considerando-se que há apenas duas razões concebíveis para que um bem fique de fora do index, a saber, a de que a sua distribuição seja regulada com exclusividade pelo princípio das liberdades básicas ou que se trate de um

\footnotetext{
${ }^{19}$ É a Versão Simples do princípio da diferença que Taylor (2004) tem em vista ao defender a primazia da EIO com base no interesse pela autorrealização.

${ }^{20}$ Para exemplos de aplicação do princípio da diferença na Versão Complexa, ver Freeman (2007, p. 113), O’Neill (2008, p. 47-52; 2012, p. 87-91) e Arnold (2012).
} 
bem ao qual uma concepção de justiça deva permanecer alheia a fim de não incorrer em perfeccionismo. Essas duas razões impedem que um bem pertença ao rol cuja distribuição o princípio da diferença regula, mas também tornam o bem em questão inapropriado para um argumento rawlsiano em defesa da ESO, no primeiro caso devido à primazia do princípio das liberdades básicas, no segundo pela sua incompatibilidade com uma concepção neutra de justiça.

Embora a Versão Complexa faça surgir a necessidade de trade-offs entre os bens componentes do index, essa versão é conciliável, dadas as circunstâncias que tornam a concepção especial de justiça aplicável, com a ideia de que certa distribuição das chances de ocupar posições de vantagem tenha prioridade sobre a maximização das expectativas dos cidadãos em pior situação quanto à riqueza e à renda. À medida, no entanto, que essa prioridade seja justificada pela relação entre as referidas chances e certos bens primários (sejam eles bens atrelados a posições de vantagem, sejam bens que as chances de ocupar essas posições diretamente proveem), a ESO em questão deve ser entendida não como princípio independente e lexicamente superior, mas como parte do princípio da diferença.

\section{CONCLUSÃO}

Este trabalho tratou de uma alternativa suficientista ao princípio da equitativa igualdade de oportunidades (EIO), a equitativa suficiência de oportunidades (ESO). Afirmei que a ESO é menos vulnerável a três problemas que afligem a EIO, os Problemas do Nivelamento por Baixo, da Classe Média e do Custo. Disse, também, que certos Argumentos de Bens Atrelados apresentados em favor da EIO são mais apropriados para a justificação da ESO. Outros argumentos, os Argumentos de Competição Justa, são no mínimo compatíveis com a preferência por um estado de coisas no qual a ESO seja atendida a outro em que as chances de ocupar posições de vantagem sejam desiguais e isso não ocorra. Além disso, Argumentos de Competição Justa que apelam para o valor derivado das referidas chances também podem ser aptos a justificar não a EIO, mas a ESO.

Distinguiram-se, ainda, duas versões do princípio da diferença, uma Versão Simples, na qual o princípio em questão se limita a requerer a maximização das 
expectativas dos cidadãos em pior situação quanto aos bens primários da riqueza e da renda, e outra, a Versão Complexa, em que essa mesma maximização se refere a um index de bens do qual a riqueza e a renda são apenas parte. Observei então que a prioridade léxica da ESO sobre a Versão Simples do princípio da diferença não parece difícil de defender nas circunstâncias do que Rawls designa como concepção especial de justiça (as únicas sob as quais são válidas as relações de prioridade léxica entre os princípios da justiça). Na Versão Complexa, em contrapartida, a ESO é mais propriamente entendida como parte do princípio da diferença ao invés de como princípio que lhe seja lexicamente superior. Ela é importante, não obstante, como limite aos trade-offs envolvendo, de um lado, a riqueza e a renda e, de outro, os demais bens primários aos quais as chances de ocupar posições de vantagem estão direta ou indiretamente relacionadas.

\title{
FAIR SUFFICIENCY OF OPPORTUNITY
}

\begin{abstract}
The article presents some problems facing Rawls's fair equality of opportunity principle. It claims that an alternative principle of sufficiency, "fair sufficiency of opportunity" (FSO), is less vulnerable to those problems. It further points out that some of the arguments employed in support of equality of opportunity look more promising when taken as arguments favoring a principle of sufficiency such as FSO. Finally, the paper also clarifies why FSO may be understood either as a principle which is lexically prior to the difference principle or as a constitutive part of the latter.
\end{abstract}

Keywords: Equality of Opportunity; Rawls; Sufficientarianism; Egalitarianism; Difference Principle

\section{REFERÊNCIAS BIBLIOGRÁFICAS}

ALEXANDER, Larry. Fair Equality of Opportunity: John Rawls' (Best) Forgotten Principle. Philosophy Research Articles, v. 11, p. 197-208, 1986.

ARNESON, Richard. Against Rawlsian Equality of Opportunity. Philosophical Studies, v. 93, p. 77-112, 1999.

Good Enough' Is Not Good Enough. In: KAUFMAN, Alexander (org.). Capabilities Equality: Basic Issues and Problems. Londres: Routledge, 2005, p. 17-43. 
Equality of Opportunity: Derivative, not Fundamental. Journal of Social Philosophy, v. 44, n. 4, p. 316-330, 2013.

ARNOLD, Samuel. The Difference Principle at Work. Journal of Political Philosophy, v. 20, n. 1, p. 94-118, 2012.

BLACK, Sandra E.; DEVEREUX, Paul J. Recent Developments in Intergenerational Mobility. Discussion paper series. Forschungsinstitut zur Zukunft der Arbeit, n. 4.866. Disponível em: http://hdl.handle.net/10419/36911. Acesso em: 5 nov. 2014.

BRIGHOUSE; Harry; SWIFT, Adam. Equality, Priority, and Positional Goods. Ethics, v. 116, n. 3, p. 471-497, 2006.

CASAL, Paula. Why Sufficiency Is Not Enough. Ethics, v. 117, n. 2, p. 296-326, 2007.

FREEMAN, Samuel. Rawls. Nova York: Routledge, 2007.

HUSEBY, Robert. Sufficiency: Restated and Defended. Journal of Political Philosophy, v. 18, n. 2, p. 178-197, 2010.

O'NEILL, Martin. Three Rawlsian Routes Towards Economic Democracy. Revue de Philosophie Économique, v. 8, n. 2, p. 29-55, 2008.

2012. Free (and Fair) Markets Without Capitalism: Political Values, Principles of Justice, and Property-Owning Democracy. In: O'NEILL, Martin; WILLIAMSON, Thad. (orgs.). Property-owning democracy: Rawls and beyond. Malden: Blackwell, 2012, p. 75-100.

PARFIT, Derek. Equality and Priority. Ratio (new series), v. 10, p. 202-221, 1997.

RAWLS, John. A Theory of Justice. 2. ed. Cambridge: Belknap Press, 1999.

Justice as Fairness: A Restatement. Cambridge: Belknap Press, 2001.

SHIELDS, Liam. The Prospects for Sufficientarianism. Utilitas, v. 24, n. 1, p. 101-117, 2012.

SHIFFRIN, Seana Valentine. Race, Labor, and the Fair Equality of Opportunity Principle. Fordham Law Review, v. 72, n. 5, p. 1.643-1.675, 2004.

TAYLOR, Robert S. Self-Realization and the Priority of Fair Equality of Opportunity. Journal of Moral Philosophy, v. 1, n. 3, p. 333-347, 2004.

TEMKIN, Larry S. Equality, Priority, or What? Economics and Philosophy, v. 19, p. 61-87, 2003.

Trabalho enviado em o5 de novembro de 2014.

Aceito em 05 de dezembro de 2014. 